\title{
REVIEWING STATUTORY MODELS OF MEDIATION/CONCILIATION IN NEW ZEALAND: THREE CONCLUSIONS
}

\author{
Claire Baylis*
}

In the last two decades there has been a trend in New Zealand of enacting statutory models of mediation/ conciliation. This article raises concerns about the treatment of fundamental process issues in the many statutory models and the inconsistencies between the models. The article is based on current research by the author which will be completed by the end of 1999. Some funding for this project has been gratefully received from the Victoria University of Wellington Foundation through the New Zealand Institute for Dispute Resolution.

\section{INTRODUCTION}

In New Zealand there are currently approximately thirty statutes which contain some type of mediation or conciliation model of dispute resolution. ${ }^{1}$ This move towards the formalisation of informal and alternative dispute resolution (ADR) processes has taken place over almost twenty years ${ }^{2}$ and reflects and builds upon a trend in many western countries of the mainstreaming of these processes. While there are many advantages to such a move, a detailed examination of the different mediation/conciliation models enacted in our statutes suggests that there are some problematic aspects to the models as they currently stand. An analysis of these problems leads to three specific but interrelated conclusions.

* Senior Lecturer in Law, Victoria University of Wellington, Deputy Director, New Zealand Institute of Dispute Resolution. I would like to thank Mr Ian Macduff of the Law Faculty and Mr David Hurley of the Employment Tribunal for their comments on an earlier draft of this article and Kerensa Johnston and Caroline Hicks for their research assistance.

1 There are also some regulations which contain models such as the Schedule to the Sharemilking Agreements Order 1990 and the Kiwifruit Marketing Regulations 1977.

2 Note though that specialised conciliation in an industrial relations context in New Zealand is much older, see Industrial Conciliation and Arbitration Act 1894. 
The first conclusion is that there is a wide divergence among the models of mediation/conciliation and that often this appears to be largely arbitrary, rather than being based on any specific thinking about the nature of the disputes in each different area. This is not only confusing to participants and lawyers involved in the processes, but it may mean that the models themselves are not working as effectively as they could be.

Secondly, this divergence becomes all the more problematic because many of the models contain features which arguably fundamentally affect the fairness and effectiveness of the process to such a degree as to throw into doubt its legitimacy as a model of mediation/conciliation. Many of these features have been identified as being contentious, both by international theorists and practitioners in the dispute resolution field and by New Zealand commentators during the recent consultation process on the Courts Consultative Committee (CCC) proposal to increase the use of mediation in civil cases. $^{3}$

Finally, there is a worrying trend that appears to be occurring in that the models which have been more recently enacted are increasingly likely to be lacking in substantive detail. I am not suggesting by this that there is a consensus as to how a model of mediation/ conciliation should be structured; a skim through the submissions on the CCC discussion paper proves that this is not the case. Rather, I would contend that there are some features of mediation/conciliation that are so inherently necessary to the process that to ignore or dispense with them, without explicit and very thorough justification based on the characteristics of the type of dispute, again fundamentally affects the fairness and effectiveness of the process itself. It may seem paradoxical to contend that certain features are essential given that mediation/conciliation is a supposedly informal and flexible dispute resolution mechanism, but when a process is institutionalised as part of the state sanctioned dispute resolution system in an area, I believe that there is a place for such an analysis. Further, I am not suggesting that there is no room for flexibility in the detail of the process, but that thorough justifications should be available before some features of the process are altered or ignored.

Each of these three conclusions will be discussed in turn, and illustrated by reference to a variety of the statutory models. Due to space considerations I will focus predominantly on one example of each conclusion, although in fact for each there are a range of other examples.

3 Courts Consultative Committee Court Referral to Alternative Dispute Resolution: Discussion Paper (1997). 


\section{DIVERGENCE WITHOUT JUSTIFICATION}

While there are similarities between the different models of mediation/conciliation which are established in the statutes, there are striking differences in the ways that the models approach different process issues. These differences relate to almost every area of mediation/conciliation practice including the identity of the mediator/conciliator, ${ }^{4}$ whether the mediation/conciliation is compulsory or voluntary, whether and how the statute deals with confidentiality and privilege, how any agreement is to be enforced, and what happens if the process fails to achieve a settlement. When the variety of areas covered by the statutes is considered it is not totally surprising to find some divergence. However, it is my belief that the range of approaches in the legislation to these issues is not based on a considered analysis of the specific characteristics of the disputes in each area, but rather that it is largely random. Yet if some models work more effectively in some types of disputes than others, a more integrated and considered approach to the drafting of these models is essential.

Perhaps one of the most fundamental examples of this divergence of approaches is the terminology which is used in the models including the name used for the process itself. Terms used in the statutes include conciliation, ${ }^{5}$ mediation, ${ }^{6}$ facilitation, ${ }^{7}$ prehearing meetings ${ }^{8}$ and settlement conferences. ${ }^{9}$

Some differentiation may be wise due to the specifics of the models established. For example the term "pre-hearing meeting" in the Resource Management Act 1991, established for consent authorities considering resource consent applications, not only allows a broader scope for the purpose of the meeting including "clarifying" as well as "mediating, or facilitating resolution of any matter or issue", 10 but it also signifies to a

4 I do not mean here the specific identity of each mediator/conciliator, but rather such issues as whether the mediator/conciliator is a judge, an official in the area, a specifically appointed mediator/conciliator or a private practitioner, and whether the statute specifies any specific qualifications necessary for the role.

5 For example the Human Rights Act 1993, s 80 and 81, the Medical Practitioners Act 1995, s 94 and the Veterinarians Act 1994, s 271.

6 For example, the Children Young Persons and their Families Act 1989, s 170, which actually uses the term mediation conference, the Residential Tenancies Act 1986, s 76, the Employment Contracts Act 1991, s 80 and the Treaty of Waitangi Act 1988, s 9A.

7 Resource Management Act 1991, s 268.

8 For example, the Resource Management Act 1991, s 99.

9 Privacy Act 1993, ss 74 and 76.

10 Resource Management Act 1991, s 99(1). 
participant a feature which is made explicit in a later subsection, that a hearing can still take place even if a settlement is achieved at that meeting. ${ }^{11}$ This model ensures that participation in any mediation is truly voluntary as parties can refuse to participate but still have the right to be heard by the consent authority. ${ }^{12}$ The model also protects the public interest in environmental issues as any settlement reached between the parties is not directly enforceable as a consent authority decision, the authority still has the duty to have regard to a range of specific matters. ${ }^{13}$ This duty ensures that the authority considers the legality of the settlement in terms of its compliance with regulations and policy statements made under the Resource Management Act 1991. It also enables the authority to look behind the agreement and ask participants how the settlement takes account of factors such as the effect on the environment or the principles of the Treaty of Waitangi and to consider whether all the interests which should have been represented were taken into account. This statutory model then, in this regard at least, is formulated on the basis of specific features of environmental and planning disputes.

The most prevalent terminological distinction in the statutes though is between conciliation and mediation and here, difficulties do occur. Many commentators recognise the difficulty of distinguishing between the two processes. ${ }^{14}$ The commonly identified reason in the literature for a distinction is that conciliation allows the third party to advise on substantive matters as well as the process, while mediation requires the third party to address process issues only. ${ }^{15}$ If this is the intended difference (and later I will argue that

11 A consent authority can still hold a meeting either IF it thinks it is necessary or if an applicant or a person who has made a submission requests to be heard (Resource Management Act 1991 ss 99(3) and 100), in which case the outcome of the meeting is circulated to all parties and to the consent authority prior to the hearing and is part of the information which the authority "shall have regard to in its consideration of the application" (Resource Management Act 1991 s 99(3)).

12 Resource Management Act 1991, s 100. Also s 99(1) states that the consent authority may "invite anyone..." to a pre-hearing meeting (emphasis added).

13 See Resource Management Act 1991 s 104 and Part II of the Act.

14 For example, see P Hutcheson and S Hooper "Mediation" in P Spiller (ed) Dispute Resolution in New Zealand (Oxford University Press, Auckland, 1999) 57, 58; H Astor and C Chinkin Dispute Resolution in Australia (Butterworths, Sydney, 1992) 61; and J Wade "Mediation - The Terminological Debate" (1994) 5 Australian Dispute Resolution Journal 204, 206. Wade identifies sets of variables of skills, processes and protocols which may occur within the process of mediation, and he suggests that conciliation too, has the "same abacus of variables" making the meaning of the terms difficult to clarify.

15 For example see Australian National Alternative Dispute Resolution Advisory Council (NADRAC) definitions as quoted in "Towards consistency in ADR terms" (1998) 1 ADR Bulletin 7, 8. This reasoning is consistent with the submission from LEADR to the CCC which defines conciliation as "occur[ing] in a statutory context where the conciliator who has duties imposed by statute, adopts an advisory approach and may even make recommendations on settlement". 
it is an inappropriate distinction in the statutory context), it should be explicit in the legislation as this is highly significant in setting the duties and the boundaries of the role of the third parties under either process, yet this is not the current situation. It appears that the distinction is understood in this way by the Human Rights Commission, for example Geraldine Whiteford of the Commission writes: ${ }^{16}$

Conciliation of complaints is based on the principles of mediation, that is, the process whereby

a neutral third party assists two parties in dispute to communicate, negotiate, and reach an

agreement or settlement. However, in the Commission's case the conciliation occurs within a

legal framework and any agreement must accord with the Act. Although the complaints officer

must be impartial, he or she can give guidance on the sorts of settlements that could be made if

the complaint were to be heard by the Complaints Review Tribunal.

The statute itself, though, does not make the distinction clear. The only detail as to the functions and duties of the conciliators is expressed merely as that the person must "use their best endeavors to achieve settlement". ${ }^{17}$ Other statutory models use this or a similar phraseology in relation to the term "mediation". ${ }^{18}$ Indeed the only statute which sets out the duties and functions of a third party in more detail is the Residential Tenancies Act 1986 which establishes a model of mediation but states that Tenancy Mediators may "make such suggestions and recommendations and do all such things as they think right and proper for inducing the parties to come to a fair and amicable settlement". ${ }^{19}$ This wording and the fact that this is a separate function to "assist[ing] the parties in bringing about a settlement" 20 makes it highly probable that this provision gives the mediators the power to give substantive advice, proving that at least in terms of that statute the distinction is not valid.

LEADR "Submissions to Courts Consultative Committee on Court Referral to Alternative Dispute Resolution" in Submissions to Courts Consultative Committee on Court Referral to Alternative Dispute Resolution (1997). It is also consistent with the National Working Party on Mediation adopted definition of mediation focussing on a process-centred approach, to distinguish it from other processes including conciliation, in National Working Party on Mediation Guidelines for Family Mediation: Developing Services in Aotearoa - New Zealand (Wellington, Butterworths, 1996) 5. See also J Riekert "ADR in Australian Commercial Disputes: Quo Vadis?" (1990) 1 Australian Dispute Resolution Journal 31,33 and particularly H Astor and C Chinkin Dispute Resolution in Australia (Butterworths, Sydney, 1992) $61-64$.

16 G Whiteford "The Complaints Procedure Under the Human Rights Act 1993" (1998) 4 Human Rights Law and Practice 47, 49.

17 Human Rights Act 1993, ss 80(2)(b), 81(1) and (2).

18 For example the Treaty of Waitangi Act 1988, s 9B.

19 Residential Tenancies Act 1986, s 76(5)(b).

20 Residential Tenancies Act 1986, s 76(5)(a). 
In addition, the distinction itself is questionable in the context of the statutory models. In reality I suspect many mediators operating under a statutory framework give substantive advice to some degree and arguably so they should. For a mediator appointed under a statute to allow a settlement which does not comply with the legislation because they are not meant to comment on the substance of the dispute would be an absurdity. To suggest that a process established under a statute to deal with disputes on matters which the Act regulates should allow settlements which do not comply with that legislation defies logic.

This absurdity can be further illustrated by a comparison of two statutory models. If the giving of substantive advice is the key difference between conciliation and mediation, this means that the legislature deemed it appropriate that under the Medical Practitioners Act 1995, a Complaints Assessment Committee consisting of two medical practitioners and a lay person ${ }^{21}$ be able to give substantive advice during a conciliation of a medical disciplinary case, while a judicial mediator appointed under the Family Proceedings Act $1980^{22}$ be restricted from giving such advice.

If the giving of substantive advice is not the intended difference between the two terms then either there is another difference which is even less clear, ${ }^{23}$ or the terms are being used largely interchangeably as they are in the United Kingdom. ${ }^{24}$ The latter is more likely, but it is baffling and it detracts from the supposedly user-friendly advantages of the processes.

Other statutory models use the terms in an even more fundamentally confusing manner which undermines even a basic understanding of the nature of these ADR processes. For example the Fire Service Act 1975 states that a "Rural Fire mediator appointed under this section shall be appointed to investigate and determine" specified

21 Medical Practitioners Act 1995, s 88, although note also that under s 89, the CAC can appoint a legal assessor to advise them on matters of law, procedure or evidence.

22 Family Proceedings Act 1980, s 14. The Children Young Persons and their Families Act 1989 and the Personal Protection of Property Rights Act 1988 use the same models of mediation with a Family Court Judge mediator.

23 N Mulcahy suggests in his article "Conciliation and Race Complaints" (1992) 3 Australian Dispute Resolution Journal 21, 22-23 that the difference between these two processes may be that the Commissioner under the Australian Racial Discrimination Act 1975 is bound to attempt conciliation while mediation is usually consensual. This distinction too, does not hold true in the New Zealand statutes as some have mandatory models of mediation, for example the Family Proceedings Act 1980.

24 H Astor and C Chinkin Dispute Resolution in Australia (Butterworths, Sydney, 1992) 61. 
matters ${ }^{25}$ and that the decision of these mediators is "final and conclusive" subject to appeal rights exercisable within one month. ${ }^{26}$ Clearly the process which is intended here is not mediation but a hybrid of mediation and arbitration in which case it should be explicitly identified as such. ${ }^{27}$

The Australian National Alternative Dispute Resolution Advisory Council (NADRAC) has recognised the need for common understandings of the different ADR processes, by recently producing a set of definitions covering the range of processes. It is essential that to achieve public acceptance and understanding of the various processes people must be clear about any significant differences. It is my belief, that in New Zealand the public, many lawyers and even some mediator/conciliators are not clear about the distinctions drawn in the statutory models.

A better alternative would be that all such processes, particularly when incorporated into legislation, use a standard general definition such as that adopted by NADRAC for statutory conciliation: ${ }^{28}$

Statutory conciliation is a process in which the parties to a dispute which has resulted in a complaint under a statute, with the assistance of a neutral third party (the conciliator), identify the disputed issues, develop options, consider alternatives and endeavor to reach an agreement. The conciliator has no determinative role on the content of the dispute or the outcome of its resolution, but may advise on or determine the process of mediation whereby the resolution is attempted and may make suggestions for terms of settlement, give expert advice on likely settlement terms, and may actively encourage the participants to reach an agreement which accords with the requirements of that statute.

A generic definition could achieve a consistency of approach without precluding any justified differences between models which responded to particular aspects of the subject matter involved. The example in the Resource Management Act 1991 discussed above illustrates this point.

As with this example of terminology, I would contend that it is possible to achieve a consistency of approach between the models on other process issues while still allowing

25 Fire Services Act 1975, s 64A(2). Section 64A was enacted by the Forest and Rural Fires Amendment Act 1990, s 32

26 Fire Services Act 1975, s 64A(6).

27 For example, by using the term "med-arb".

28 As quoted in "Towards consistency in ADR terms" (1998) 1 ADR Bulletin 7, 8. For the purposes of this article I will not discuss the appropriateness of this specific definition for the New Zealand context. 
enough flexibility where there is good reason for a model to approach an issue in a unique way.

\section{FUNDAMENTAL PROCESS ISSUES}

Not only are the statutory models inconsistent with each other, there are also many examples of features of the models which do not accord with much of the growing jurisprudence of mediation in legal areas. A significant contribution to this thinking in New Zealand, has taken place through the consultation process which has been conducted over the past two years on the proposal by the High Court Review Committee that judges should have the legislated power to refer cases to mediation or arbitration. Early in 1997 the Department for Courts' Policy Unit produced a discussion paper at the request of the CCC on the proposal. ${ }^{29}$ In response to this over twenty submissions were received from the judiciary, government departments and agencies, the law society, service providers and individuals. ${ }^{30}$

This consultation process is an extremely useful one, especially considering that the proposal is a major change to the way our justice system currently works. While there are already some specific areas where mediation is effectively a first stage in proceedings, the current proposal dramatically broadens the scope of mediation in civil cases. The main motivations behind the proposal are to increase the public's access to justice and to reduce the delay and cost of civil hearings. Ironically these motivations also reflect the key tension underlying the proposal, between the traditional view that a constitutional right which should not be undermined is that everyone is entitled to their day in court (a consideration which ultimately is about access to justice) and the view from the High Court Review Committee that ${ }^{31}$

Judicial time is a scarce and expensive resource. We consider that no one should be entitled to the use of Court hearing time unless and until other reasonable means of resolving the dispute have been attempted.

It is interesting that the significance of the proposal has been so clearly identified as warranting a detailed consultation process, yet the implementation of thirty statutory

29 Courts Consultative Committee Court Referral to Alternative Dispute Resolution: Discussion Paper (January 1997).

30 Department for Courts "Submissions to Courts Consultative Committee on Court Referral to Alternative Dispute Resolution" (1997).

31 Courts Consultative Committee "Court Referral to Alternative Dispute Resolution: Discussion Paper" (1997) 11. 
models of mediation over twenty years has not raised such concentrated analysis about its constitutional effects. ${ }^{32}$

Both the submissions and the original discussion paper on the CCC proposal raised a range of key issues of fundamental importance for any fair and effective model of mediation adopted in the legal arena. Yet these issues do not appear to have been carefully considered when the drafting of many of the statutory models of mediation is analysed. For example, most of the submissions discussed the issue of mandatory mediation with the prevailing view being that a voluntary system was preferable. ${ }^{33}$

Certainly there are practitioners who firmly believe that compelling parties to attend mediation is not harmful and that often with education about the process, parties can enter meaningful discussion and reach an appropriate settlement. ${ }^{34}$ Others believe that voluntariness and empowerment of the parties is at the heart of mediation itself, and is essential to ensure the rule of law. ${ }^{35}$ However, even those practitioners and theorists who do accept the usefulness of mandatory mediation, overwhelmingly do so with certain conditions attached. For example, most agree that there must still be a filtering process to ensure that inappropriate cases are not compulsorily mediated, and that there must not be inappropriate pressure to settle during the mediation. ${ }^{36}$ Both of these limitations on

32 For a discussion on this topic from the United States (and which focuses on arbitration) see R C Reuben "Public Justice: Toward a State Action Theory of Alternative Dispute Resolution" (1997) 85 Cal L Rev 577.

33 See Department for Courts Submissions to Courts Consultative Committee on Court Referral to Alternative Dispute Resolution (1997).

34 For example see CC Hutchinson "The Case for Mandatory Mediation: Practitioner's Note" (1996) 42 Loyola L Rev 85. See also T Altobelli "Mediation: Primary Dispute Resolution 1996: Mandatory Dispute Resolution in 2000?" (1997) 11 AJFL 55, 64-67 for an outline of the arguments for and against mandatory mediation.

35 See R Ingleby "Court Sponsored Mediation: The Case Against Mandatory Participation" (1993) 56 MLR 441 and T Grillo "The Mediation Alternative: Process Dangers for Women" 1006 (1991) Yale LJ 1545.

36 For example see M Vincent "Mandatory Mediation of Custody Disputes: Criticism, Legislation, and Support" 20 (1995) Vermont L Rev 255 whose article responds to feminist critiques of mandatory mediation for divorce and custody disputes. Ultimately she supports the concept of mandatory mediation but suggests that screening by mediators of each party separately is essential (288) and that parties or the mediator must be able to terminate the sessions at any time (288-290). See also CC Hutchinson "The Case for Mandatory Mediation: Practitioner's Note" (1996) 42 Loyola L Rev 85, 90. 
institutionalised mediation were highlighted in the Australian report on Access to Justice as probably requiring national minimum standards to ensure justice in this area. ${ }^{37}$

Ultimately, then, many of those involved in the mediation field view blanket compulsion to mediate as problematic, undermining central tenets of the process, yet we have statutory models which use blanket compulsion. ${ }^{38}$ The Human Rights Act 1993 is one such model as under section 81, once the investigating officer has formed an opinion and notified the parties of this, the investigating officer must conduct a conciliation. Not only does this Act remove the parties' power to refuse to participate in conciliation, but also on its face the Act removes the power of the Commission to decide that a case is inappropriate for conciliation; it does not legislate a filtering process.

I have written previously of my views of the inappropriateness of conciliation processes for sexual harassment cases. ${ }^{39}$ The notion that the Commission has to attempt conciliation in some sexual harassment cases is totally abhorrent. An example is Proceedings Commissioner $v$ Laursen ${ }^{40}$ in which an employer of a female apprentice jockey aged sixteen had "non-consensual sex" with her, then proceeded to sexually harass her for a further three years culminating in her leaving the employment pregnant. However, sexual harassment cases are not the only type of case which the Human Rights Commission may be dealing with which could be inappropriate to conciliate. ${ }^{41}$

Kressel and Pruitt suggest that: ${ }^{42}$

intensely conflicted disputes involving parties of widely disparate powers, with low motivation to settle, fighting about matters of principle... and negotiating over scarce resources are likely to defeat the most adroit mediators!

Compelling parties to mediate against their will, in situations where even the most practised mediators are unlikely to achieve a settlement fundamentally undermines both

37 Australian Access to Justice Advisory Committee Access to Justice: An Action Plan (National Capital Printing, Australia, 1994) 295.

38 Human Rights Act 1993, ss 80 and 81, the Privacy Act 1993, s 77.

39 See C Baylis "The Inappropriateness of Mediation for Sexual Harassment Complaints" (1997) 27 VUWLR 585.

40 Proceedings Commissioner $v$ Laursen, (7 May 1996)Complaints Review Tribunal, Decision No 1996/10.

41 For a general discussion on factors affecting the appropriateness of mediation see GR Clarke and IT Davies "Mediation - When is it not an Appropriate Dispute Resolution Process?" (1992) Australian Dispute Resolution Journal 70.

42 K Kressel and D Pruitt Mediation Research (Jossey-Bass Inc, 1989). 
the fairness and the effectiveness of the process to the point where its use may no longer be legitimate. Yet anti-discrimination cases are quite likely to involve many if not all of these factors, especially those taken by groups as test cases, such as the case of $R v W$ $L t d .{ }^{43}$ This was a dispute between parties of widely disparate power, a group of individuals, some of whom were sickness beneficiaries, complaining against a large and expanding corporation. The complainants were wheelchair users and contended that an order of 80 new buses by the company, which would replace half its fleet, breached the Human Rights Act 1993 sections 42, 44 and 65 as discrimination in the provision of services or access by the public to vehicles. The complainants claimed that the buses should be super-low floor buses which would make them wheelchair accessible as well as more easily accessible to those with other mobility disabilities and caregivers with prams. The Company claimed that the expense of such buses was not financially viable to them and that therefore they fell within the section 52 exception within the Act.

Following the investigation the full Commission formed the opinion that the Company had not established that they fell within the exception and upheld the complaint. The complainants in the case did not want to then conciliate for the very reason that they were aiming at a judicial pronouncement on the rights of those with disabilities. Many of the complainants had initially hoped that this case would act as a precedent for transport providers, and also for any service providers who were not achieving substantive equality of access for those with disabilities.

This type of case also illustrates another reason why some cases may not be appropriate for settlement processes. The aim of conciliation is not to set any general norms, dealing instead with the specific parties involved. ${ }^{44}$ This individualisation of outcome results, in a situation like this, in the necessity for groups with disabilities to complain and go through conciliation with each industry of service providers and even each individual or Company separately rather than achieving a broad-brush stroke for campaigners for the rights of those with disabilities.

Compelling parties to attend conciliation is problematic, but to impose a statutory duty on the Commission to conciliate after an investigation undermines the fundamental fairness of the process. While different people may come to different conclusions on what factors should exclude a case from conciliation, this does not justify blanket compulsion. It suggests only that it is a difficult issue which requires the development of policy based

43 As summarised in Human Rights Commission "Human Rights Act Updates - Notes on Significant Opinions of the Human Rights Commission" (1995) 1 Human Rights Law and Practice 115, 117-119.

44 For a fuller discussion of this point see JA Scutt "The Privatisation of Justice: Power Differentials, Inequality, and the Palliative of Counselling and Mediation" (1988) 11 Women's Studies Int Forum 503. 
on practical experience and consultation. Even a simple provision may be enough, such as that enacted by the Health and Disability Commissioner Act 1994 which imposes a gate-keeping role on the Commissioner stating that the Commissioner should only call a mediation conference when the Commissioner "is of the opinion that it is appropriate to do so". ${ }^{45}$ Enacting gatekeeping/screening provisions in legislation is also consistent with overseas approaches to this issue. In the United States, at the end of 1995, of 22 States with mediation programmes for divorce and custody disputes only California had a mandatory model which did not have some sort of screening programme or waiver for abusive relationships. ${ }^{46}$ In Australia, 1996 regulations under the Family Law Act 1975 set out "a prescribed minimum of topics for discussion during an assessment or screening" 47 including "a history of family violence...the equality of bargaining power...and the emotional, psychological and physical health of the parties...." 48 Similar factors could be incorporated into the Human Rights Act 1993.

Blanket compulsion to mediate is one example of a process issue which has been legislated in such a way as to fundamentally undermine the fairness and effectiveness of mediation/conciliation. While those working in the field may not agree entirely on what other issues are regarded as intrinsic to the process, to consult and debate on this question would certainly lead to improvements in the drafting of the various models. Many would agree that some form of enforceability of any settlement that is achieved through mediation is another issue which is fundamental to the process. Similarly, trained and accountable mediators who are impartial (if not neutral) ${ }^{49}$ and the identification and inclusion of all relevant parties to a dispute are likely to be viewed as fundamental process issues. In the statutory setting, clear and explicit provisions on privilege and confidentiality are to my mind essential. Yet it appears that while there is a growing body of theoretical discussion about ADR, the drafting of models of mediation in New Zealand statutes is not improving in terms of these process issues. In fact there is an increasing lack of detail in the models so that many of these issues are not referred to at all in some of the most recent enactments and it is this trend to which I will now turn.

45 Health and Disability Commissioner Act 1994, s 61(1).

46 Cal Civ Code § 4607. See also M Vincent "Mandatory Mediation of Custody Disputes: Criticism, Legislation, and Support" 20 (1995) Vermont L Rev 255, 272-273 and Appendix B 293- 297.

47 J Wade "Family Mediation: A Premature Monopoly in Australia" (1997) 11 AJFL 286, 291.

48 Family Law Regulations 1996 reg 62(2), made under the Family Law Act 1975 (Cth).

49 See ABA Standards of Practice for Family Mediators in Divorce (1984) 17 FLQ 455, 457 which suggests "Impartiality is not the same as neutrality. While the mediator must be impartial as between the mediation participants, the mediator should be concerned with fairness. The mediator has an obligation to avoid an unreasonable result." 


\section{AN INCREASING LACK OF DETAIL}

The references in statutes to some form of settlement process can be categorised broadly into three varieties of models, although there are a few anomalies. The first and least common type imposes a duty that in any instrument of a particular variety established under the Act, certain specifics as to mediation must be set out in that instrument. In other words these Acts legislate that models of mediation be established in instruments created under the Act. For example, under the Commodity Levies Act 1990 every levy order established pursuant to the Act must provide for the appointment of mediators to resolve disputes as to whether a levy is owed and the amount to be paid. The order must detail the procedure for the mediators to follow, their remuneration, the payment of mediation costs and a right of appeal to a District Court Judge. ${ }^{50}$ One noteworthy aspect of this model is that the right of appeal is "against decisions of mediators" which as discussed above throws into question the legislative intention when establishing the procedure and again reiterates the need for clear and consistent terminology throughout the legislative references.

The second type of model is where the statute imposes a duty on an official under the legislation to attempt settlement, but does not give any detail as to how that duty should be carried out. The statutes which contain such references use both mediation and conciliation terminology. All of the Acts using this variety of model have been passed since $1989 .{ }^{51}$ Such references are highly problematic as they give no guidance on fundamental process issues.

Finally the most common variety of references in statutes is where the legislature has attempted to detail, (to a varying degree) a model of mediation/conciliation to be used as the primary method of resolving disputes under the Act. Some such statutes contain very detailed models such as the Residential Tenancies Act 1986 and the Family Proceedings Act 1980, which are two of the earlier ones, while a number of the more recent models contain far less detail, for example, the Medical Practitioners Act 1995, the Health and Disability Commissioners Act 1994 and the Privacy Act 1993.

In my view all these types of references to mediation/conciliation processes should cover the fundamental process issues. However, in this third category, in which the legislature has attempted most comprehensively to set out models of mediation/conciliation, there has been an increasing lack of detail as to the process. This trend cannot be justified on the basis that statutory mediation is now well established and

50 The Commodity Levies Act 1990, s 11.

51 For example, the Crown Minerals Act 1991 s 68, the Education Act 1989, s 115, and the School Trustees Act 1989, s 22 (which deals with transitional matters). 
process issues have been dealt with elsewhere. First, as has been discussed the models are so varied in the way that they deal with these process issues that it is impossible to suggest that any consistent approach has been established by earlier models which could be implicitly adopted by the later ones. Secondly, the more recent models do tackle some process issues but ignore other key issues.

The Residential Tenancies Act 1986 is the most detailed of the statutory models, containing approximately 1,600 words establishing the model, and covering issues such as the appointment of Tenancy mediators, ${ }^{52}$ their duties, functions and powers, ${ }^{53}$ privilege and confidentiality, ${ }^{54}$ enforceability of settlement, ${ }^{55}$ and the procedure to be followed if a settlement cannot be reached. ${ }^{56}$ In contrast, the Medical Practitioners Act 1995 deals specifically with conciliation in approximately 160 words bestowing the power that Complaints Assessment Committees can use conciliation and setting out the basic procedure if settlement is reached or is not reached. The Act gives no indication as to the type of process envisaged, when it should be used, or how any settlement that is reached is made enforceable.

Similarly the Health and Disability Commissioner Act 1994 (HDC Act) deals with mediation conferences in one section and while again some process issues are dealt with, the Act is silent on many others. Interestingly the HDC Act provides some detail which many other Acts do not cover, such as the procedure for calling a mediation conference, a basic gate-keeping provision, the explicit authorisation for parties to be legally represented and a provision for the payment of fees or expenses to the parties and their representatives as if they were witnesses in a Court. ${ }^{57}$ The Act also allows the Commissioner to invite any other person to attend the mediation if in her or his opinion this is "likely to assist in resolving the matter by agreement between the parties."158 However, this recent Act, too, fails to address fundamental issues which should be part of any statutory model. The Act is silent as to whether the Commissioner can compel the parties to attend a mediation conference, whether the Commissioner must record any

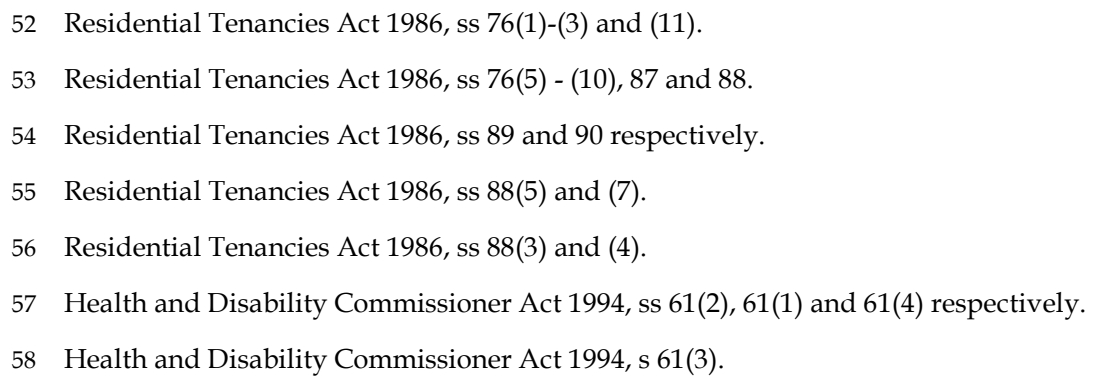


settlement which is reached, and whether and how the parties can enforce such a settlement.

It is ironic that it is in the health complaints area that two of the most recent statutory models inadequately deal with process detail, because part of the impetus for legislative reform in the area was a recognition of the significant public interest in getting the complaint procedure right. ${ }^{59}$ As a consequence of the Cartwright Inquiry into the treatment of cervical cancer patients at National Women's Hospital in $1988^{60}$, the Health and Disability Commissioner's office was established and the medical complaint procedures were overhauled to ensure the complaint process is seen as non-partisan, is fair, expeditious and easily accessible. ${ }^{61}$ Another key factor was that the process should not be financially burdensome on the taxpayer or the complainant. ${ }^{62}$

Mediation of some health complaints can be advantageous in achieving a speedy and relatively cheap resolution of the more minor complaints without unnecessarily formal procedures. The particular provisions of the HDC Act's model does respond specifically to some of the identified reasons for reform; for example by allowing other parties to be invited to attend the mediation, and for the payment of fees and expenses. However, by not explicitly dealing with some key process issues there is a danger that the process will not be effectively and fairly used and will not achieve the specific goals established during the revamp of the processes.

The drafting of mediation models should be improving as we come close to nearly twenty years of statutory mediation, yet this is not the case. There may be disagreement on the way to approach some process issues but this is no reason to ignore them entirely. If mediation is to be a fair and empowering process of dispute resolution, any statute which encompasses it must cover clearly and explicitly all the fundamental process issues which are involved.

\section{CONCLUSION}

In examining and analysing all the references to mediation/conciliation in our statutes it is clear that the way that process issues are legislated is rather random and

59 See Peter Cartwright "The Role and Scope of the Medical Practitioners Disciplinary Tribunal" (1997) II R Medico Legal Conference.

60 S Cartwright The Report of the Committee Of Inquiry Into Allegations Concerning The Treatment of Cervical Cancer at National Women's Hospital and into Other Related Matters (Auckland, 1988)

61 Peter Cartwright "The Role and Scope of the Medical Practitioners Disciplinary Tribunal" Medico Legal Conference 1997 IIR, 3; Hon R Sowry MP (27 September 1994) NZPD 3743, 3746; Hon J Shipley MP (13 October 1994) 543 NZPD 4301, 4303.

62 Above $\mathrm{n} 59,3$ 
increasingly lacks attention to specifics. Early statutory references to mediation/conciliation included detailed provisions covering policy issues and there was even some consistency of approach, for example the Family Proceeding Act 1980, the Children Young Persons and their Families Act 1989, and the Protection of Personal Property Act 1988 are all based on the same model.

Among some practitioners there is a kind of post-modern resistance to the notion that processes should be defined in any detail. The concern is that this will constrain any flexibility and diversity of approach. Certainly the ideal may not be the drafting of one ultimate model of statutory mediation because this would ignore too many differences in the characteristics of the disputes in the affected areas. However, when mediation/conciliation is established as part of a statutory process of dispute resolution and can affect people's rights and entitlements under the law clarity and consistency are necessary. It is my view that the legislative models are in need of reform to achieve this, and that any new statutory mediation/conciliation models need to be drafted so as to achieve clear consistent use of terminology, and a standard approach to process issues. This consistent approach should only then be deviated from if there is good reason due to either the characteristics of disputes in an area, or the specific features of the other forms of dispute resolution mechanisms under the statute. 